\title{
Clloboll Britojis
}

Covnpetitive Age and

Deffence on a Competitive

Age: A Critigue

By Anthony h. Cordesman

Working Draft: July 29, 2021

Please provide comments to acordesman@gmail.com

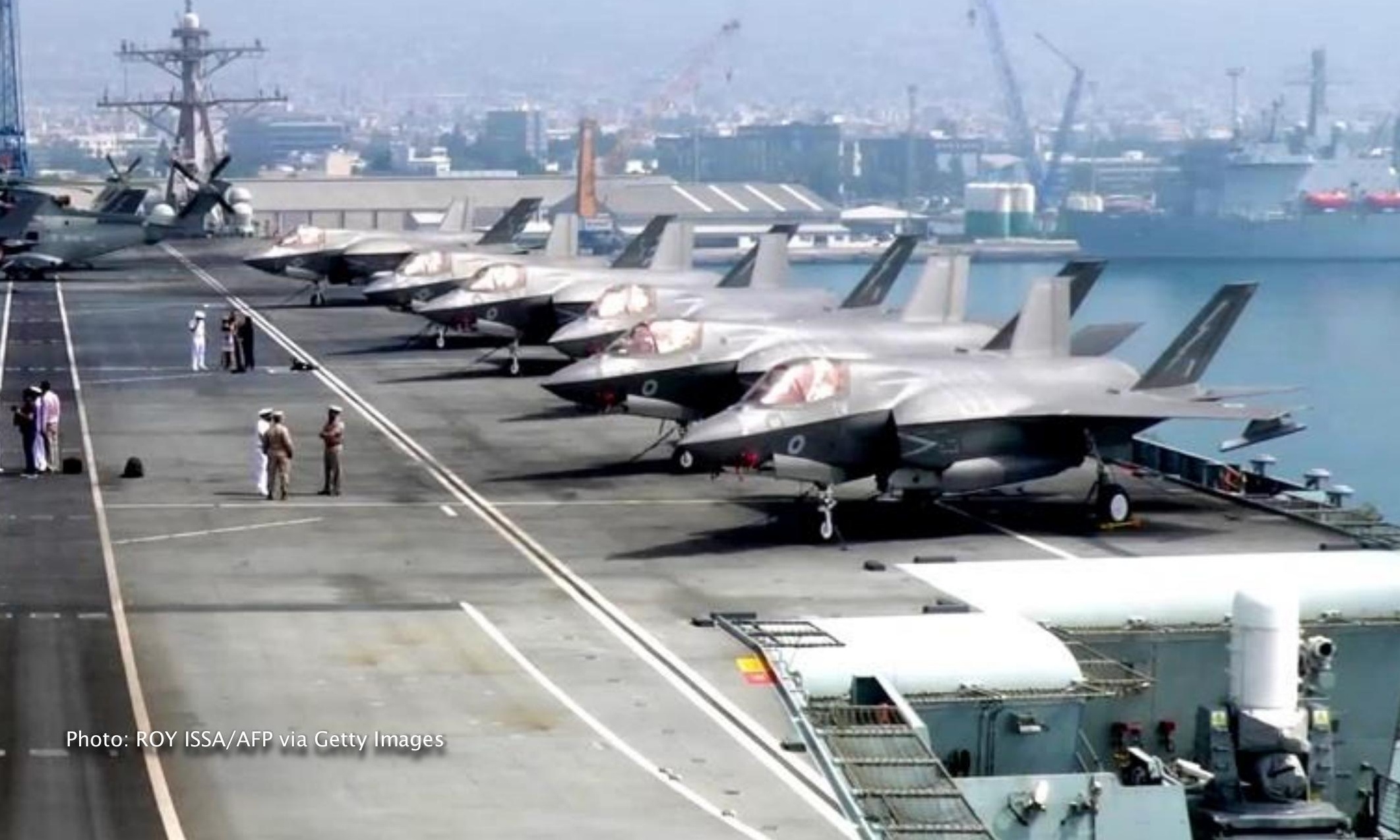




\section{Global Britain in a Competitive Age and Defence in a Competitive Age: A Critique}

\section{Anthony H. Cordesman, Burke Chair in Strategy, CSIS}

The white papers Britain issued in 2021 - Global Britain in a Competitive Age and Defence in a Competitive Age - do not serve their claimed purpose. They do not provide a meaningful "integrated review" of British defense, and they fail to properly address most of the challenges raised in the House of Common's commentary - In Search of Strategy-The 2020 Integrated Review. Instead, they are filled with vague good intensions, rhetoric, and goals, but they lack any of the specifics. Both documents mention the need for serious study and analysis, but they are 109and 71-page vacuums when it comes to providing such content.

Global Britain in a Competitive Age touches on idea after idea without defining specific courses of action, and it sometimes seems to be more of a catalog of strategic options focusing more attention to full color photos than a real effort at strategy. The closest it comes to specifics is listing the areas of added spending in Annex A: Integrated Review priorities funded in Spending Review 2020, but this annex provides no real specifics as to how and when this money will be spent and does not even show that the money will be adequate to meet its intended purpose.

Defence in a Competitive Age does list most of the key strategic challenges that Britain faces and does list some force improvements, specifics, and spending data. However, it does not present clear overall force plans or supporting details describing plans, programs, implementation schedules, budgets, or measures of effectiveness.

\section{The Collective Failures in Western Strategic Planning}

In fairness, there is nothing unique about the limited substantive content of both papers. They are all too typical of most Western white papers and national defense budgets. They are mirror images of the faults in most U.S. strategy and budget documents since the end of the Cold War, and especially since the beginning of America's long wars in 2001. These U.S. documents include America's various Quadrennial Defense Reviews, the National Strategy and National Defense Strategy issued by the Trump administration, and the initial annual budget and strategy statements issued by the Biden administration. These U.S. documents do have some specific plans and budgets, but they still fall far short of presenting real strategies.

The same is true of far too much NATO reporting, which either provides equally vague strategic rhetoric or focuses on budget size and burdensharing in terms of percentages of GDP and equipment spending. Like the British and American strategy documents, they fail to provide any real net assessments of the balance; analyses of trends in the threat; or the lack of progress in coordinating interoperability, modernization, and an effective structure for NATO-wide deterrence and defense.

NATO's military and Secretary General have often focused on real military goals, but NATO Ministers have not reviewed and approved meaningful force plans, called for serious efforts to improve interoperability, or agreed on specific ways to modernize and cooperate in new areas of security and defense.

As for the public defense strategy documents and defense plans of other European states, they too generally fail to set meaningful goals and to provide meaningful plans. France calls for an EU approach to security and ignores the military realities of Transatlantic power. Germany's defense 
documents have done nothing to end the steady decline of Germany's status as the core of central Europe's regional land and air strength. Furthermore, the uncoordinated plans and spending of most other individual NATO states continue to present serious problems on a country-by-country basis.

\section{Creating Meaningful Approaches to Permanent and Persistent Engagement, and Rethinking Deterrence}

This broad lack of meaningful strategy and plans for cooperation at the highest political levels in the West makes it all too clear that Britain - as well as the United States and far too many other Atlantic powers - do need to focus on how to approach permanent and persistent engagement as well as how to rethink deterrence.

To do this, however, Western countries need to recognize that the world, the global balance of military and economic power, technology, and the nature of modern military forces are evolving so quickly that national and NATO security strategies must be based on a clearly defined set of plans, programs, implementation schedules, budgets, and measures of effectiveness.

Such efforts must also take into consideration the present plans, programs, and budgets in ways that look far enough into the future to show what their impact will really be. They must assess the threat, the role of partners and allies, and the key area of focus and projected rates of change which in the U.S. is called the future year defense plan (FYDP). At the same time, anyone who actually work on such plans realizes that the pace of change is now so high that such efforts require regular annual updating.

Reality does far more to shape strategy than strategy does to shape reality. Hoping that any given strategy can safely remain unchanged and survive engagement with reality for more than a year or two defies that reality. Strategy documents not only need to describe real strategies, they need to be modified and "rolled" forward on an annual basis. Their future five year plans need to be updated, along with supporting net assessments. They cannot afford to gloss over further force cuts and losses of readiness, the inability to properly execute key areas of modernization, and the failure to bring new programs in at the estimated numbers and effectiveness.

\section{Global Britain in a Competitive Age and Defence in a Competitive Age as Test Cases}

Here, Global Britain in a Competitive Age and Defence in a Competitive Age make good examples of the need for change and for examining the narcissism and blind-spots in addressing opportunities, requirements, and capabilities.

\section{- Looking Beyond "Strategic Jingoism" and Burdensharing}

"Narcissism" - staring at oneself in a mirror to the point where one becomes fixated and starves to death - may seem to be an odd term for strategic analysis, particularly when coupled to "blind spots." Yet the British strategy documents - like the U.S., French, German, and most other strategy documents and white papers - really only address British defense and strategy in an era of alliances and strategic partnerships. This does equate strategic nationalism with strategic narcissism

Here, an American must temper such comments about the British papers with the observation that the U.S. has been the worst example of such strategic narcissism for at least the past four years of the Trump administration. America's self-seeking transactional approaches to NATO and strategic 
partnerships focused on $2 \%$ and $20 \%$ burdensharing. They did so without making any serious effort to set clear priorities for what to buy, and they never addressed the need to find the best ways for the U.S. and its strategic partners to implement the new National Strategy and National Defense Strategy that the Trump administration announced in its first two years of office.

Worse, the resulting burdensharing efforts never addressed the fact that the U.S. and British intelligence communities - as well as several leading think tanks like the International Institute for Strategic Studies (IISS) and Stockholm International Peace Research Institute (SIPRI) - estimated that Russia was only spending $\$ 65$ to $\$ 100$ billion on military forces a year. In contrast, NATO reported spending a total of \$302-\$363 billion a year for NATO Europe and Canada in 2019-2021, and $\$ 730$ billion to $\$ 811$ billion for United States in 2019-2021.

Given the fact these figures indicate that NATO Europe alone consistently spent more than three times as much as Russia during 2014-2021, the U.S. should have focused on how NATO could have spent more wisely - and on producing a stronger and better integrated collective effort - not blindly asking for more spending.

\section{- Focusing on "Global Britain"}

The British white papers do emphasize Europe and NATO, and they do list some important areas of activity in improving forward defense, air/missile defense, and naval capabilities. They do not suggest in any way that "Brexit" should be followed by "NAxit."

Defence in a Competitive Age states quite clearly that, "The UK has an unwavering commitment to NATO and remains bound to the requirement for collective self-defense under Article V of the Washington Treaty: that an attack on one NATO Ally shall be considered an attack on all. To underpin the credibility of our deterrence posture, we will maintain well-supported and equipped nuclear and conventional forces at high readiness, across all domains, capable of high- intensity warfighting. We will design our warfighting forces to be integrated with allies, first and foremost through NATO, acting as a framework nation (providing the lead command and enabling function to NATO) to command and cohere Alliance warfighting activity."

However, the references the two white papers make to a broader global role from Britain are sometimes so broad and vague that they seem to be a reminder that at least some Britons feel that one of God's greatest mistakes was putting Britain only 22 miles away from the mainland of Europe. Such a focus on "Global Britain" is only marginally better than Trump's focus on burdensharing. Britain can play a key role by demonstrating a global presence, but its central priority must be Europe, NATO, the Atlantic, and the Mediterranean.

Moreover, Britain needs a strategy that does not ignore the fact that European defense is in deep disarray when it is examined on a country-by-country basis. This disarray shows up in simple ways in the very different force cuts that European powers have made since the break-up of the former Soviet Union (FSU), in the lack of standardization and interoperability in far too many force plans, and in patterns of modernization that preserve national differences rather than reinforce collective deterrence and defense.

It is reflected in President Macron's idea of an independent EU defense structure in spite of the EU's limited forces, and particularly in France's current posture in the central region. It is apparent in the steady decline in the size of Germany's forces and deterrent capabilities. Moreover, far too many other European countries present major problems if one examines their individual force 
structures, especially in the former Warsaw Pact states; in the lack of a clear mission for key elements of the forces of Italy, Spain, and Portugal; and in the changing role of Turkey.

Britain also cannot ignore the fact that U.S. strategy has changed to focus on the emergence of China as a potential peer competitor and on radical shifts in the balance of power in Asia that now make China a key focus for U.S. strategy, force planning, and developing strategic partnerships and alliances.

Where Britain can now play a truly critical international role is in pushing for an effective Transatlantic alliance; keeping the U.S. focused on Europe as well as on China; pushing NATO into effective net assessments; and conducting a new NATO force planning exercise on a nationby-nation basis that is supported by effective planning, programing, planning, and budgeting. The future of the British army presented in Defence in a Competitive Age needs particularly careful review in this context. It seems to present still further force cuts as if they were force improvements.

\section{- The Danger in Projecting Power Too Far East of Hormuz and Too Close to China}

Other aspects of British "globalism" present problems. Global Britain in a Competitive Age does stress the growing power of China, but it then does little more than call for added trade and investment activity everywhere outside Europe and for an "Indo-Pacific Tilt" through undefined new trade agreements. Defence in a Competitive Age also notes the "rising power of China," "the significant impact of China's military modernization," and its "growing international assertiveness." However, it then fails to provide more than a few sentences of supporting analysis or indication of how Britain plans to respond. Here, the word "global" may well be little more than strategic overreach.

Britain can serve a useful political and diplomatic purpose through demonstrative deployments in the Pacific, but it will be far more cost-effective in deterring and defending China if it can buildup its strength - and that of other European powers - in the Atlantic and the Mediterranean in ways that allow the U.S. to safely deploy more forces to the Pacific and to work with Australia, New Zealand, and other Asian powers to deter and contain China.

Sustaining a warfighting presence in Asia in any serious conflict pushes British resources to - or beyond - their limit. Trying to deploy British forces like it single carrier task force - which could play a major role and survive in many contingencies in the Atlantic and the Mediterranean - could all too easily repeat Britain's loss of two battleships - the Prince of Wales and the Repulse - in the Pacific in WWII.

This is not simply a function of limited global power projection capability, but of changes in military technology and force capabilities. Like the U.S., Britain needs to be more careful about the future nature of naval warfare. The old joke that "a yacht is a hole in the water into which you pour money," may gradually be replaced by the all too serious risk that "a carrier has become a hole in the water into which an enemy pours missiles."

Referencing the Five Eyes (Australia, Canada, New Zealand, the U.K. and the U.S.) also has its limits. It seems all too likely that only Australia and the U.S. can be serious Pacific powers, and that any major partners will be Japan, Korea, India, other Asian and Pacific powers, and the Arab Gulf States. 
In contrast, Britain clearly does have the resources and location to play a critical role in bringing NATO and Europe together; in the Atlantic region; in dealing with the changing role of the Arctic and Iceland/Greenland gap; in work with Norway, the Baltic states, and non-NATO powers like Sweden and Finland; in work with Mediterranean powers like Italy, Spain, and Portugal to help secure the Mediterranean; in dealing with issues like Greece and the changing regional role of Turkey; and in strengthening deterrence in the Arab/Persian Gulf and MENA region.

These are issues that are touched upon briefly in Section 5.7 of Defence in a Competitive Age, but only briefly and without any references to the major problems and incompatibilities in the defense efforts of key NATO powers. Focusing Britain's strength in the area where it can be most effective at reducing the pressure on the U.S. to defend the Atlantic and Europe will allow it to commit more forces to the Pacific and Asia as well as to aid Australia, New Zealand, and other British strategic partners in the process.

\section{- Nuclear Modernization to Deter What? Britain's Role in Long-Range Conventional Strike Forces?}

One of the areas where Defence in a Competitive Age does provide some detail is British nuclear modernization. However, it only justifies this modernization by saying that Britain's nuclear forces "remains essential as the ultimate guarantee to our security, and that of our allies." It also mentions that nuclear forces respond to the fact that the "technical advantage of the U.K. and its allies has diminished over the past two decades, challenged by targeted investment in capabilities designed to counter our strengths and target our weaknesses," but it provides no details as to why they provide such benefit.

Neither Global Britain in a Competitive Age, nor Defence in a Competitive Age provide a clear picture of how British nuclear forces do or do not provide extended deterrence in Europe; are linked to French and U.S. nuclear capabilities; and relate to the rapidly developing mix of longrange and global Russian, Chinese, and U.S. conventional prompt strike and long-range ballistic missile systems - as well as any efforts at arms control.

This evolving mix of new nuclear and conventional forces is already a key aspect of strategic change. Over the next five years, it will alter the balance in NATO and the rest of Europe as well as the force structure of other modern military powers - including those of the U.S., China, and Russia. It may well create a world where an independent European long-range or even global conventional strike capability plays a more important role in the overall spectrum of deterrence than nuclear forces, or is at least as important as nuclear strike capabilities.

\section{- Creating New Military Forces and Capabilities}

The two white papers do briefly raise key shifts in military technology that are now changing force planning in ways that are at least as radical as the rise of air power and armored warfare before World War II. Yet, Section 1.1 of Global Britain in a Competitive Age largely ignores these issues and talks about growing the UK's science and technology power in terms of spending percentages of GDP. It provides no real specifics other than a paragraph on page 72 that seems to promise advances in every major area of military capability without providing a single meaningful specific.

Defence in a Competitive Age does talk briefly about the range of new technologies shaping deterrence and defense like cyber, space, missiles, air/missile defense, and many other areas. It also warns that Britain's, "approach to warfare has evolved relatively slowly in recent years, while our adversaries have invested in equipment and forces that expose our vulnerabilities. They are 
committed to understanding our capabilities and activities, adapting their approach to enable them to win without warfighting. They have increased their focus on speed and readiness."

“...They are prepared to use hard military force to confront us, if they deem it necessary, either directly or through proxies. Failure to adapt our armed forces' posture, skills and capabilities to the changing environment and threat will hand the advantage to our adversaries. Our armed forces must have the tools and capabilities they need to lead, influence, partner, deter and when necessary to fight to ensure the whole of the UK and its interests are protected. We cannot afford to stand still while the world changes around us. We must change how we deter our adversaries, defend our nation and our nation's interests."

It then goes on to state that Britain is "Evolving from a force that is primarily designed for the contingency of a major conflict and warfighting, to one that is also designed for permanent and persistent global engagement. To succeed in the era of systemic competition we will need to be front-footed. We and our allies and partners must drive the tempo of strategic activity rather than responding to others."

It states that Britain will need to be. "Integrated across all 5 domains - space, cyberspace, maritime, land and air. We will go beyond the traditional concept of 'joint' to a depth of multidomain integration that adds up to far more than the sum of the parts." Chapter Seven of Defence in a Competitive Age also presents a long series of statements about improvements in key areas.

However, Defence in a Competitive Age does not present any real plans for such changes or for the integration of new weapons and technology across the military services and the major branches within them. Like the U.S. focus on Joint All Domain Operations (JADO) it does not address the plans for action, budgets, time scales, and the shifts that will be needed in every element of command and control; battle management; and intelligence, surveillance, and reconnaissance (IS\&R).

Like similar U.S. strategic prose, the discussion is again somewhat narcissistic. It does not address the need to be able to interoperate on a fundamentally different level with allied powers once these shifts are made - a challenge that makes the lack of radio communications in French armored forces at the start of World War II seem like a minor issue by comparison.

Many NATO countries - and most military forces outside NATO - will not be able to match Britain and the U.S. in creating such capabilities - while those that do may often create major new security issues in cooperating with other states. Moreover, this evolution in military forces will inevitably affect all levels of deterrence and conflict, and escalation management.

\section{- Soft Power Tokenism, the Defense Industrial Base, and STEM Capability}

The references to "soft power" and Britain's financial strength in Global Britain in a Competitive Age describe real potential sources of power. Yet, they ignore the growth of China's financial, manufacturing, and technology base; the growing links between China and Russia; and China's growing ability to exploit its trade links and investment in belt and road efforts in other countries. They do not describe any real-world scenarios; examine Britain's capability to act alone or at an incremental value; and ignore the steadily shrinking global share of Britain and Europe's science, technology, engineering, and mathematics (STEM) capabilities.

"Soft power" will be a growing issue in future white area, gray area, and irregular warfare - as well as in shaping higher levels of deterrent capability - but treating it as some kind of hollow 
rhetorical tool is as dangerous for Britain as it is for the United States and the West. Russian economic pressure is so far limited, but its military technology and manufacturing remain competitive. Furthermore, ignoring the strength of China's "belt and road" initiatives, STEM efforts, and major gains in its global ranking as a military industrial base is actively dangerous.

\section{- Assessing Past and Future Progress}

Strategy is not an exercise in rhetoric, it is an exercise in action. It must be addressed in terms of force trends and of the shifts in force size, success in modernization, trends in readiness, and net assessments of the resulting shifts in the balance of deterrence and defense. It must examine past and future trends in spending as well as the ability to manage costs and key force changes. Most notably, it should provide tangible and specific goals for measuring future success.

The two British white papers do virtually none of this, although again U.S. and NATO documents are at best only marginally more successful. One only has to look at the problems in ship design and building, combat aircraft fleet modernization, and the modernization of major land weapons to see how serious these problems now are, and how urgent it is to address them openly and effectively.

\section{Creating A Reality-Based Strategy}

In summary, Britain, the U.S., and NATO do not need broad statements of strategic good intentions and generalities. Substituting political glitz for substance is dangerous to national security. It simply is not enough to say that, "The Prime Minister's commitment to spending $£ 188$ bn on Defence over the coming four years - an increase of $£ 24 \mathrm{bn}$ or fourteen per cent - is an investment in that vision of security and prosperity in 2030. Previous reviews have been over-ambitious and under-funded, leaving forces that were overstretched and under-equipped. But the Integrated Review's refreshed strategy and increased funding offers Defence an exciting opportunity to turn hollow forces into credible ones, modernizing for the threats of the 2020s and beyond, and contributing to national prosperity in the process."

National strategy and defense white papers must provide all the necessary details. They must recognize that any effective strategy must now deal with a world where major shifts are taking place in the global balance of power that are at least equal to those that took place in the early 1930s, and where the nature of military forces is changing at least as rapidly in technology, tactics, and cost.

Building effective national strategies and effective national forces requires building an open political consensus around practical strategies based on detailed net assessments to justify detailed defense plans. It requires clearly defined implementation plans, credible budgets based on honest projections of cost and schedules that make key future changes, and adequate summary measures of effectiveness.

There also are better tools and ways to do this. Defence in a Competitive Age does note that the Ministry of Defense has created a Secretary of State's Office for Net Assessment and Challenge (SONAC) "Given the complex, multifaceted challenges that we face, strategic decision making in the MOD must be guided by clear objectives, threat-focused and evidence-driven. We are establishing the SONAC which will bring together the best of the civil service, armed forces, academia and business..." 
"SONAC will challenge the accepted wisdom and way of doing things. The unit will provide a central hub for strategic analysis in our Head Office, ensuring that our strategy and joint force development remains threat and evidence- led, now and in the far future. It will develop new ways to understand the threat, including by incorporating a Net Assessment approach to assess how we compare to adversaries now and in the future. It will ensure we learn the strategic lessons from our own activity, but also importantly the approaches of other international actors."

What Defence in a Competitive Age does not explain is why SONAC has failed to play a substantive play role in the current white papers, or what role it will play in publicly justifying Britain's strategy, force plans, and budget in the future. And here, the U.S. provides another bad example and warning. The U.S. has failed to incorporate net assessment in its open source justification of its defense budgets and strategy documents, and the end result is that they lack critical parts of the content they need to explain and to justify major decisions.

Adequate strategy papers must address key net assessment issues and allow detailed outside commentary, criticism, and suggestions of their content - particularly in a world where classifying broad shifts in strategy and forces is impossible. Secrets still need to be kept from potential threats when they can. Classifying what every competent hostile power can almost immediately learn is largely an exercise in dodging legitimate investigation, challenge, and criticism from one's own and allied national experts and from opposition political parties.

Strategy, plans, and the programs to implement them as well as the budgets to fund them need to be updated and revised on an annual basis, along with projections of at least the near-term future. This means institutionalizing serous annual strategic reviews and putting ministers, commanders, and official plans and analyses on the spot. It means annual net assessments must explain the trends in the balance and consider allies and partners. These also are areas where providing semi-official annual reviews and assessments, and where evaluations from outside think tanks and opposition political parties are equally critical.

Anthony H. Cordesman holds the Arleigh A. Burke Chair in Strategy at the Center for Strategic and International Studies in Washington, D.C. He has served as a consultant on Afghanistan to the United States Department of Defense and the United States Department of State. 